\section{REFERENCES}

Dixon, O. G. (1949). J. Soc. chem. Ind., London., 68, 88.

Dorinson, A., McCorkle, M. R. \& Ralston, A. W. (1942). J. Amer. chem. Soc. 64, 2739.

Francis, F. \& Piper, S. H. (1939). J. Amer. chem. Soc. 61, 577.

Francis, F., Piper, S. H. \& Malkin, T. (1930). Proc. Roy. Soc. A, 128, 214.

Gray, F. V., Pilgrim, A. F., Rodda, H. J. \& Weller, R. A. (1951). Nature, Lond., 167, 954.

Hansen, R. P. \& McInnes, A. G. (1954). Nature, Lond., 173, 1093.

Hansen, R. P., Shorland, F. B. \& Cooke, N. J. (1954a). Biochem. J. 58, 513.

Hansen, R. P., Shorland, F. B. \& Cooke, N. J. (1954b). Nature, Lond., 174, 39.

Hansen, R. P., Shorland, F. B. \& Cooke, N. J. (1954c). Biochem. J. 58, 516.
Hansen, R. P., Shorland, F. B. \& Cooke, N. J. (1955). Chem. \& Ind. p. 92.

Hilditch, T. P. (1947). The Chemical Constitution of Natural Fats, 2nd ed. London: Chapman and Hall Ltd.

James, A. T. \& Martin, A. J. P. (1952). Biochem. J. 50, 679.

Levene, P. A. \& West, C. J. (1914). J. biol. Chem. 16, 475.

Links, J. \& de Groot, M. S. (1953). Rec. Trav. chim. Pays$B a s, 72,57$.

Meyer, J. D. \& Reid, E. E. (1933). J. Amer. chem. Soc. 55, 1574.

Morice, I. M. \& Shorland, F. B. (1954). Quoted by Hansen, R. P., Shorland, F. B. \& Cooke, N.J.(1954c). Biochem. J. 58,516 .

Shorland, F. B. (1952). J. appl. Chem. 2, 438.

Shorland, F. B., Bruce, L. W. \& Jessop, A. S. (1952). Biochem. J. 52, 400.

Shorland, F. B., Gerson, T. \& Hansen, R. P. (1955). Biochem. J. 59, 350.

Slagle, F. B. \& Ott, E. (1933). J. Amer. chem. Soc. 55, 4396. Weitkamp, A. W. (1945). J. Amer. chem. Soc. 67, 447.

\title{
Studies in the Biochemistry of Micro-organisms
}

\section{THE COLOURING MATTERS OF PENICILLIUM HERQUEI BAINIER \& SARTORY*}

\author{
By J. A. GALARRAGA, K. G. NEILL AND H. RAISTRICK \\ Department of Biochemistry, London School of Hygiene and Tropical Medicine, University of London
}

(Received 25 April 1955)

One of the four major sections-the BiverticillataSymmetrica-into which Raper \& Thom (1949) divide all species in the genus Penicillium was designed by them to include species having, among other characteristics, biverticillate conidial structures which are usually symmetrical. They state (p. 558): 'Penicillia can almost invariably be placed here if they produce... aerial hyphae more or less yellow pigmented and encrusted and colony reverse in yellow, orange or red to purplish red shades.'

Workers in this laboratory have isolated in pure crystalline form the colouring matters produced, by a number of well-defined species of Biverticillata-Symmetrica from three of the six series into which this major section is divided. These colouring matters, although often showing clear signs of chemical inter-relationship, belong to a number of different chemical types. Thus stipitatic acid, $\mathrm{C}_{8} \mathrm{H}_{6} \mathrm{O}_{5}$, from the bright-yellow $P$. stipitatum Thom in the P. luteum series (Birkinshaw, Chambers \& Raistrick, 1942) is $\beta$-hydroxytropolone- $\beta^{\prime}$-carboxylic acid, which is pale yellow in colour. Another bright-yellow species in the same series, $P$. wortmanni Klöcker, afforded two crystalline

* Part 95: Breen, Dacre, Raistrick \& Smith (1955). colouring matters-rugulosin, $\mathrm{C}_{30} \mathrm{H}_{22} \mathrm{O}_{10}$, forming bright-yellow cubes or prisms, and skyrin, $\mathrm{C}_{30} \mathrm{H}_{18} \mathrm{O}_{10}$, reddish orange rods (Breen et al. 1955). Seven different pigments were isolated from strains of $P$. islandicum Sopp in the $P$. funiculosum series, colonies of which vary in colour from yelloworange through orange-red to red. They were: islandicin, bright-red plates, $\mathrm{C}_{15} \mathrm{H}_{10} \mathrm{O}_{5}$, 1:4:5-trihydroxy-2-methylanthraquinone (Howard \& Raistrick, 1949); chrysophanol, golden plates, $\mathrm{C}_{15} \mathrm{H}_{10} \mathrm{O}_{4}$, 4:5-dihydroxy-2-methylanthraquinone (Howard \& Raistrick, 1950); skyrin and flavoskyrin, $\mathrm{C}_{15} \mathrm{H}_{12} \mathrm{O}_{5}$, light-yellow needles, of unknown structure but converted almost quantitatively into chrysophanol on heating (Howard \& Raistrick, 1954a); iridoskyrin, deep-red plates, $\mathrm{C}_{30} \mathrm{H}_{18} \mathrm{O}_{10}$; rubroskyrin, dark-red plates, $\mathrm{C}_{30} \mathrm{H}_{22} \mathrm{O}_{12}$; and erythroskyrin, dark-red micro-crystals, and the only pigment in this series containing nitrogen, $\mathrm{C}_{24} \mathrm{H}_{31} \mathrm{O}_{6} \mathrm{~N}$ (Howard \& Raistrick, 1954b). Rubroskyrin is readily converted, by treatment with concentrated sulphuric acid at room temperature, into iridoskyrin and, inter alia, into islandicin, by thermal decomposition. Finally, rugulosin and skyrin were also isolated from $P$. rugulosum Thom, in the $P$. rugulosum series, colonies of which have yellow to orange-brown, but seldom a red, reverse (Breen et al. 1955). It will 
thus be seen that skyrin is a colouring matter which is common to some species in each of the three series examined and that rugulosin is common to two series. Neither the molecular structure of skyrin nor that of rugulosin has yet been determined, but it is already clear that they must both be structurally related to some of the other colouring matters described, which are substituted polyhydroxyanthraquinones, since skyrin is smoothly converted, at room temperature by sodium dithionite, into two molecules of emodin (4:5:7-trihydroxy-2-methylanthraquinone) and rugulosin can be converted, also by simple processes though less efficiently, into chrysophanol and emodin.

Work was commenced here in 1950 on the colouring matters of a strain of Penicillium herquei Bainier \& Sartory, a member of the $P$. herquei series of the Biverticillata-Symmetrica, and two crystalline colouring matters were soon isolated from this strain, which are quite different from any of those mentioned above. While this work was in progress, a preliminary announcement of work on the pigments of $P$. herquei appeared (Stodola, Raper \& Fennell, 1951) in which one unnamed pigment was described, having the empirical formula $\mathrm{C}_{20} \mathrm{H}_{20} \mathrm{O}_{7}$ and melting at 225-227 ${ }^{\circ}$ (decomp.), which was clearly identical with one of the two pigments isolated here. From subsequent correspondence it transpired that Dr Stodola had arranged for further studies on this colouring matter, now named herqueinone, to be carried out by Professor James Cason, Department of Organic Chemistry, University of California, Berkeley, U.S.A. Through the courtesy of Dr Stodola it has been arranged that the American workers' findings and our own should be published simultaneously.

Members of the $P$. herquei series 'are easily recognized, for the bright yellow-green colours that characterize the vegetative mycelium, and usually the colony reverse, are not encountered elsewhere in the genus Penicillium' (Raper \& Thom, 1949, p. 658). Our strain of $P$. herquei, S.M. 138, was grown on Raulin-Thom solution at $24^{\circ}$ in the dark. After 21-28 days' incubation, the yellowish green mycelium, with a bright brownish red reverse, was collected, washed with water and dried in vacuo at 40-45 ${ }^{\circ}$. The dried mycelium was extracted with cold chloroform and the green extract was evaporated in vacuo to low bulk, when a considerable quantity of herqueinone, $\mathrm{C}_{20} \mathrm{H}_{20} \mathrm{O}_{7}$, separated in red needles and was collected. The solvent was removed from the chloroform mother liquors and the dark greenish residue was freed from 'fat' by washing with light petroleum. The resulting dark bluish green amorphous powder remaining contains a complex mixture of colouring matters, only one of which has been isolated in a state of purity. It has been identified as physcion, 4:5-dihydroxy-7methoxy-2-methylanthraquinone, i.e. the 7-methyl ether of emodin.

The chloroform-extracted mycelium was now dried and re-extracted exhaustively with ether, giving good yields of a brick-red crystalline colouring matter, which has not been described previously and for which we propose the name norherqueinone, with the empirical formula $\mathrm{C}_{19} \mathrm{H}_{18} \mathrm{O}_{7}$. Along with this colouring matter, the ether extract also contained appreciable amounts of mesoerythritol, $\mathrm{C}_{4} \mathrm{H}_{10} \mathrm{O}_{4}$, butane-1:2:3:4-tetraol, colourless tetragonal plates, m.p. $120-124^{\circ}$. This substance, which is of frequent occurrence in algae and lichens, was first described as a mould metabolic product from laboratory cultures of Penicillium brevi-compactum Dierckx and $P$. cyclopium Westling (Oxford \& Raistrick, 1935).

The total weight of colouring matters which are extractable by organic solvents from the dried mycelium of many of the species of Penicillium in the Biverticillata-Symmetrica which we have examined is often very surprisingly large. Thus, with strain N.R.R.L. 1036 of $P$. islandicum, $201 \mathrm{~g}$. of dried mycelium yielded $44.92 \mathrm{~g}$. ( $\equiv 22 \cdot 3 \%$ ) of crude colouring matter; with strain S.M. 1 of $P$. rugulosum, $200 \mathrm{~g}$. of dried mycelium gave $45 \cdot 0 \mathrm{~g}$. ( $\equiv 22.5 \%$ ) of crude crystalline rugulosin; and with strain 138 of $P$. herquei, $335 \mathrm{~g}$. of dried mycelium gave a total of $56 \cdot 45 \mathrm{~g}$. ( $\equiv \mathbf{1 6 \cdot 8} \%$ ) of crude colouring matters.

\section{HeRqueinone}

Herqueinone, $\mathrm{C}_{20} \mathrm{H}_{20} \mathrm{O}_{7}$, melts with decomposition, at about $226^{\circ}$. It sublimes in high vacuum at 175-190 . Solutions of herqueinone in ethanol are strongly dextrorotatory. The molecule of herqueinone contains a minimum of three hydroxyl groups, one methoxyl group and at least two methyl groups attached to carbon. It dissolves in aqueous sodium hydroxide, giving a bright-orange solution which rapidly fades to pale yellow, but does not dissolve in sodium carbonate solution. A solution in cold concentrated sulphuric acid is a rather weak orange with a slight yellow fluorescence which is intensified to a strong green on standing for some days. In ethanolic solution it gives a ferric reaction which appears brownish olive by transmitted light but is almost black by reflected light.

The following functional derivatives of herqueinone have been prepared: trimethyl ether $\mathbf{A}$, $\mathrm{C}_{23} \mathrm{H}_{28} \mathrm{O}_{7}$, pale-yellow rods, m.p. $345^{\circ}$; trimethyl ether $\mathrm{B}, \mathrm{C}_{23} \mathrm{H}_{28} \mathrm{O}_{7}$, colourless rods, m.p. $170-171^{\circ}$. Both the trimethyl ethers are optically inactive and insoluble in aqueous sodium hydroxide, and give negative ferric reactions in ethanol.

Herqueinone is readily converted into an optically inactive isomer, isoherqueinone, orange 
needles, m.p. $248-249^{\circ}$, by boiling its acetone solution for $1 \mathrm{hr}$. over solid anhydrous potassium carbonate. Hence it appears probable that both the trimethyl ethers, $A$ and B, are in fact ethers of isoherqueinone. isoHerqueinone strongly depresses the melting point of herqueinone $\left(226^{\circ}\right)$ on admixture with it, but gives reactions with cold concentrated sulphuric acid, aqueous $2 \mathrm{~N}$ sodium hydroxide and ferric chloride in ethanol which are indistinguishable from those given by herqueinone with the same reagents.

The infrared absorption spectra of herqueinone and isoherqueinone in dilute chloroform solution were identical, within the limits of experimental error, indicating that the change from herqueinone to isoherqueinone is a steric change and that no fundamental rearrangement has taken place.

When a solution of herqueinone in glacial acetic acid is treated with zinc dust at room temperature, a reduction product, deoxyherqueinone, $\mathrm{C}_{20} \mathrm{H}_{20} \mathrm{O}_{6}$, is formed. This substance, which forms yellow plates, m.p. $240-241^{\circ}$, still contains the methoxyl group which is present in the parent substance. It is dextrorotatory, dissolves in aqueous $2 \mathrm{~N}$ sodium hydroxide giving a pale-yellow solution, but does not dissolve in sodium carbonate. Its reactions with cold concentrated sulphuric acid and ferric chloride in ethanol are almost indistinguishable from those given by the parent substance.

A crystalline product containing bromine is formed when saturated bromine water is added, at room temperature, to an ethanolic solution of herqueinone. This substance, to which the empirical formula $\mathrm{C}_{8} \mathrm{H}_{8} \mathrm{O}_{4} \mathrm{Br}_{2}$ is tentatively assigned, still contains a methoxyl group. It forms colourless needles, m.p. $189-190^{\circ}$ (decomp.), which give a moderate purplish brown ferric colour in ethanolic solution.

When a suspension of herqueinone in aqueous $2 \mathrm{~N}$ sulphuric acid is boiled for some hours, hydrolysis of the herqueinone takes place according to the following equation, only negligible amounts of carbon dioxide being formed:

$$
\mathrm{C}_{20} \mathrm{H}_{20} \mathrm{O}_{7}+\mathrm{H}_{2} \mathrm{O} \rightarrow \mathrm{C}_{5} \mathrm{H}_{10} \mathrm{O}+\mathrm{C}_{15} \mathrm{H}_{12} \mathrm{O}_{7} .
$$

The substance $\mathrm{C}_{5} \mathrm{H}_{10} \mathrm{O}$, which was first isolated as the 2:4-dinitrophenylhydrazone, was identified as methyl isopropyl ketone. This identification was confirmed by the preparation of its semicarbazone.

The substance $\mathrm{C}_{15} \mathrm{H}_{12} \mathrm{O}_{7}$ appears not to have been described previously and, because of its colour, we propose to call it xanthoherquein. It forms goldenyellow needles, m.p. 295-296 ${ }^{\circ}$ (decomp.), and the molecule contains one methoxyl group and one methyl group attached to carbon. It is readily soluble in aqueous sodium bicarbonate, giving a yellow solution which changes to orange-red on standing. Its solution in cold concentrated sulphuric acid, initially greenish yellow in colour with a strong yellow-green fluorescence, slowly becomes orange on long standing. It gives a strong olive-green ferric colour in ethanolic solution. The following functional derivatives have been prepared: xanthoherquein perchlorate,

$$
\mathrm{C}_{15} \mathrm{H}_{12} \mathrm{O}_{7}, \mathrm{HClO}_{4}, \mathrm{H}_{2} \mathrm{O} \text {, }
$$

red to orange-brown rectangular plates, m.p. $244^{\circ}$ (decomp.); xanthoherquein tetramethyl ether, $\mathrm{C}_{19} \mathrm{H}_{20} \mathrm{O}_{7}$, bright-yellow needles, m.p. 141-142 ${ }^{\circ}$, insoluble in aqueous alkalis, but, paradoxically, extractable from ether solution by $2 \mathrm{~N}$ sodium hydroxide but not from chloroform solution; it gives a brown ferric colour in ethanol; xanthoherquein tetramethyl ether ferrichloride,

$$
\mathrm{C}_{19} \mathrm{H}_{20} \mathrm{O}_{7}, \mathrm{HFeCl}_{4} \text {, }
$$

orange-brown needles, m.p. 158-159 .

When a solution of herqueinone in aqueous sodium hydroxide is heated in an atmosphere of nitrogen, the breakdown of the colouring matter follows a completely different course from that of the acid hydrolysis. Acetaldehyde is formed in good yield in place of methyl isopropyl ketone, but neither xanthoherquein nor any other pure crystalline breakdown product has at present been isolated.

\section{NORHERQUEINONE}

The brick-red crystalline material obtained by prolonged ether extraction of the chloroformextracted mycelium contained a hitherto undescribed colouring matter, which we have named norherqueinone, because, as will be shown later, herqueinone is its monomethyl ether. Norherqueinone, $\mathrm{C}_{19} \mathrm{H}_{18} \mathrm{O}_{7}$, crystallizes in dark-red needles, m.p. $279^{\circ}$ (decomp.), solutions of which in pyridine are very strongly dextrorotatory, $[\alpha]_{\mathrm{D}}+1080^{\circ}$. It is almost insoluble in the usual organic solvents. It gives reactions with alkalis and with cold concentrated sulphuric acid which are very similar to those given by herqueinone, but its intense olivegreen ferric reaction in ethanol is a much clearer green.

Unlike herqueinone, norherqueinone does not contain a methoxyl group, but the relationship between the two substances is evident from the fact that on methylation it gives a tetramethyl ether, $\mathrm{C}_{19} \mathrm{H}_{14} \mathrm{O}_{3}\left(\mathrm{OCH}_{3}\right)_{4}$, pale-yellow plates, m.p. $341^{\circ}$, which is identical with the trimethyl ether $A$ of herqueinone.

Like herqueinone, norherqueinone is readily converted into an isomer, isonorherqueinone, $\mathrm{C}_{19} \mathrm{H}_{18} \mathrm{O}_{7}$, red needles, m.p. 284 ${ }^{\circ}$ (decomp.), $[\alpha]_{\mathrm{D}}-730^{\circ}$, whereas isoherqueinone is optically inactive. isoNorherqueinone gives reactions with alkalis, cold concentrated sulphuric acid and ferric 
chloride in ethanol which are indistinguishable from those given by the parent substance.

Norherqueinone also undergoes a similar hydrolysis, when boiled with aqueous $2 \mathrm{~N}$ sulphuric acid, to that of herqueinone with the same reagent. The reaction proceeds, in the same way as with herqueinone, according to the equation

$$
\mathrm{C}_{19} \mathrm{H}_{18} \mathrm{O}_{7}+\mathrm{H}_{2} \mathrm{O} \rightarrow \mathrm{C}_{5} \mathrm{H}_{10} \mathrm{O}+\mathrm{C}_{14} \mathrm{H}_{10} \mathrm{O}_{7} \text {, }
$$

the products of hydrolysis being again one molecule of methyl isopropyl ketone and, in this instance, one molecule of norxanthoherquein, $\mathrm{C}_{14} \mathrm{H}_{10} \mathrm{O}_{7}$, in place of one molecule of xanthoherquein.

Norxanthoherquein, which has not been described previously, forms orange-yellow plates, which do not melt below $360^{\circ}$. The molecule contains one methyl group attached to carbon but, unlike xanthoherquein, does not contain a methoxyl group. Its colour reactions, e.g. formation of a pale-yellow solution in saturated aqueous sodium bicarbonate and a yellow solution with an intense yellow-green fluorescence in cold concentrated sulphuric acid, are very similar to those given by xanthoherquein. In contrast, however, it gives with ethanolic ferric chloride a colour which is initially olive green but which changes to purple brown on standing.

The following functional derivative of norxanthoherquein has been prepared: norxanthoherquein pentamethyl ether, $\mathrm{C}_{14} \mathrm{H}_{5} \mathrm{O}_{2}\left(\mathrm{OCH}_{3}\right)_{5}$, yellow needles, m.p. $140-141^{\circ}$, identical with xanthoherquein tetramethyl ether. Xanthoherquein is thus the monomethyl ether of norxanthoherquein.

It is hoped to discuss in a later paper the bearing of the derivatives and breakdown products of herqueinone and norherqueinone on the molecular constitution of these substances.

\section{EXPERIMENTAL}

\section{Culture}

The strain of Penicillium herquei Bainier \& Sartory which was used in this investigation was isolated by Mrs S. Marcus in this Department in 1950 from a culture plate exposed at Chelsea Polytechnic, London, by Dr J. C. Dacre. It carries the London School of Hygiene and Tropical Medicine (L.S.H.T.M.) catalogue number S.M. 138. It was identified by $\mathrm{Mr}$ G. Smith of this Department.

\section{Cultural characteristics of, and pigment formation by, Penicillium herquei, strain S.M. 138}

Quantities (350 ml.) of Raulin-Thom solution (glucose, 75.0 g.; tartaric acid, 4.0 g.; ammonium tartrate, 4.0 g.; $\left(\mathrm{NH}_{4}\right)_{2} \mathrm{HPO}_{4}, 0.6 \mathrm{~g}$; $\left(\mathrm{NH}_{4}\right)_{2} \mathrm{SO}_{4}, 0.25 \mathrm{~g}$.; $\mathrm{K}_{2} \mathrm{CO}_{3}, 0.6 \mathrm{~g}$.; $\mathrm{MgCO}_{3}, 0.4 \mathrm{~g}$.; $\mathrm{FeSO}_{4}, 7 \mathrm{H}_{2} \mathrm{O}, 0.07 \mathrm{~g}$.; $\mathrm{ZnSO}_{4}, 7 \mathrm{H}_{2} \mathrm{O}, 0.07 \mathrm{~g}$.; distilled water, $1500 \mathrm{ml}$.) were distributed in a number of 1 1. conical flasks plugged with cotton wool and sterilized. Batches of 100 such flasks were inoculated with a spore suspension prepared from mature (4-5 week) cultures on beer-wort agar of $P$. herquei, strain S.M. 138, and incubated at $24^{\circ}$ in the dark.

The mould grew well on this medium and after 14 days' incubation the cultures developed a strong smell of apples, in agreement with Raper \& Thom's $(1949$, p. 659) observation. After 21 days' incubation the yellowish green mycelium was deeply folded with a bright brownish red reverse. Some areas were covered with a brownish red pigment which, under the microscope, appeared partly amorphous but with many long yellow needles. The culture fluid was moderate brown in colour, with a greenish fluorescence, and contained a number of long orange-yellow needles. A portion of the filtered culture fluid gave a clear olive-brown ferric colour, readily decolorized considerable amounts of saturated bromine water without the formation of a precipitate and, on acidification with $\mathrm{HCl}$, gave a dark-brown amorphous precipitate. Portions of the mycelium, pressed as dry as possible between layers of filter paper, gave the following reactions: with cold conc. $\mathrm{H}_{2} \mathrm{SO}_{4}$ an immediate very dark brown colour with a strong greenish fluorescence; with aqueous $2 \mathrm{~N}-\mathrm{NaOH}$ or $2 \mathrm{~N}$ $\mathrm{Na}_{2} \mathrm{CO}_{3}$ a deep-brown stable solution.

At the end of the incubation period the mycelium was separated from the culture fluid by filtration, washed well with water, pressed as dry as possible in a tincture press and finally dried in a vacuum oven at $40-45^{\circ}$.

The filtered culture fluid was shown to contain colouring matters, two of which are also present in the mycelium, by the following procedure. The culture filtrate (29.6 l., from ninety-nine flasks of batch 2 after 21 days' incubation, see Table 1) was acidified to Congo red with conc. $\mathrm{HCl}$ (75 ml.) and held for 2 days at $0^{\circ}$. The resulting brown amorphous precipitate was separated by filtration, washed and dried (15.5 g.), and part of it (4 g.) was extracted three times with boiling $\mathrm{CHCl}_{3}(80,80,160 \mathrm{ml}$.). Evaporation of the combined $\mathrm{CHCl}_{3}$ extracts gave $1 \cdot 10 \mathrm{~g}$. of red needles, m.p. $220-221^{\circ}$, raised to $227^{\circ}$ (decomp.) on recrystallization from ethanol and not depressing the m.p. $226^{\circ}$ (decomp.) of a pure specimen of herqueinone. The two specimens also gave identical colour reactions.

The clear acid filtrate from the brown amorphous precipitate (15.5 g.), which gave an olive ferric colour, was extracted twice with ether ( $\frac{1}{3}$ vol. and $\frac{1}{5}$ vol.). The extracted filtrate, which no longer gave a ferric colour, was discarded. The ether extracts were evaporated to small bulk (about $100 \mathrm{ml}$.) and held overnight at $0^{\circ}$. The crystalline colouring matter which separated $(0.78 \mathrm{~g}$.) was collected, m.p. $228^{\circ}$, depressed to $217^{\circ}$ after admixture with herqueinone. The colouring matter was fractionally crystallized from ethanol, giving two fractions, the more soluble of which consisted of herqueinone, m.p. $226^{\circ}$ (decomp.) alone or in admixture with an authentic specimen, m.p. $226^{\circ}$ (decomp.), isolated from the mycelium. The less soluble fraction $\left(0.45\right.$ g.), m.p. about $266^{\circ}$, was repeatedly crystallized from glacial acetic acid (1 l./g.), giving red needles with a metallic sheen $(0 \cdot 13$ g. $)$, m.p. $278^{\circ}$ (decomp.). A mixture of this substance with norherqueinone isolated from the mycelium, m.p. $279^{\circ}$ (decomp.), melted at $279^{\circ}$ (decomp.). The two specimens also gave identical reactions in the following tests: (i) in aqueous $2 \mathrm{~N}-\mathrm{NaOH}$, a dark-red solution fading in a few seconds to pale yellow; (ii) in cold conc. $\mathrm{H}_{2} \mathrm{SO}_{4}$, an orange-red solution changing on standing at room temperature to reddish brown with a strong green fluorescence; (iii) an intense olive-green ferric colour in ethanol solution. 
Isolation of the colouring matters from the mycelium

The vacuum-dried mycelium was immersed for $15-20 \mathrm{hr}$. in cold $\mathrm{CHCl}_{3}$ (100 ml. for the mycelium of each flask) and the mixture was shaken occasionally. The filtered $\mathrm{CHCl}_{3}$ extract was evaporated in vacuo to low bulk (250-300 ml./ 100 flasks). The dark-green concentrate, which contained much reddish crystalline material, was kept in the refrigerator to complete crystallization and was then filtered. The clean reddish crystalline material obtained was washed with cold $\mathrm{CHCl}_{3}$ and dried, giving almost pure herqueinone (fraction A 1). A second crop (fraction A 2) of only slightly less pure material was obtained on further evaporation of the dark green $\mathrm{CHCl}_{3}$ mother liquors and washings. The yield of herqueinone (fraction A $1+$ fraction A 2) obtained was $23 \mathrm{~g} .-29 \mathrm{~g}$./100 flasks. Full details of the three batches are given in Table 1.

The final $\mathrm{CHCl}_{3}$ mother liquors were evaporated to dryness in vacuo and the resulting dark residue was triturated thoroughly with light petroleum (b.p. 40-60 ) to remove fatty materials. The mixture was filtered and the undissolved portion was well washed on the filter with light petroleum and then dried, giving fraction $B$ as a dark bluish green powder (see Table 1, column 9). On removal of the solvent from the combined light-petroleum filtrate and washings there remained a residue of crude 'fat', fraction $C$ (Table 1, column 10).

The mycelium, after thorough extraction with $\mathrm{CHCl}_{3}$ as described above, was air-dried and then exhaustively extracted $(100 \mathrm{hr}$.) with ether in a Soxhlet apparatus. When so treated the $\mathrm{CHCl}_{3}$-extracted mycelium (284 g.) of the seventy-seven flasks of batch 1 gave $16.45 \mathrm{~g}$. of crystalline reddish brown colouring matter which separated from the ether extract and purification of which gave norherqueinone, m.p. $279^{\circ}$ (decomp.). On evaporation of the ether mother liquors there remained a semi-gummy residue (3.1 g.).

The dark bluish green fraction $B$ was shown, by chromatographing its $\mathrm{CHCl}_{3}$ solution on a $\mathrm{MgCO}_{3}$ column, to contain a rather intractable complex mixture of colouring matters which has not yet been fully investigated. However, one of its constituents was shown to be physcion (4:5-dihydroxy-7-methoxy-2-methylanthraquinone) by the following experiment. Fraction B from batch 1 (5 g.) was extracted twice, with $500 \mathrm{ml}$. each time of light petroleum (b.p. $40-60^{\circ}$ ), the mixtures being held at room temp. for $24 \mathrm{hr}$. with occasional shaking. The extract was evaporated to dryness, giving a partly crystalline residue which was washed with a little ether. The undissolved residue was crystallized from $\mathrm{CHCl}_{3}$, giving yellow plates $(0.03 \mathrm{~g}$.), m.p. 198-200, which were purified by sublimation in high vacuum at $125-145^{\circ}$, giving orange needles, m.p. $207-208^{\circ}$. A mixture with authentic physcion, m.p. $206^{\circ}$, from the lichen Xanthoria parietina melted at $207^{\circ}$. The two substances also gave identical reactions with the following reagents: cold conc. $\mathrm{H}_{2} \mathrm{SO}_{4}$, deep-red non-fluorescent solution; aqueous $\mathrm{N}-\mathrm{NaOH}$, red solution; aqueous $\mathrm{N}-\mathrm{Na}_{2} \mathrm{CO}_{3}$, insoluble; ethanolic $\mathrm{FeCl}_{3}$, reddish brown colour.

The major portion of the $5 \mathrm{~g}$. of fraction $\mathrm{B}$ remained undissolved. It was dried and fractionally extracted in a Soxhlet apparatus with light petroleum (b.p. $40-60^{\circ}$ ) for $37 \mathrm{hr}$. The only crystalline material which was obtained was crude herqueinone (small amounts), m.p. $216^{\circ}$. Undissolved material (3.1 g.) remained in the Soxhlet thimble.
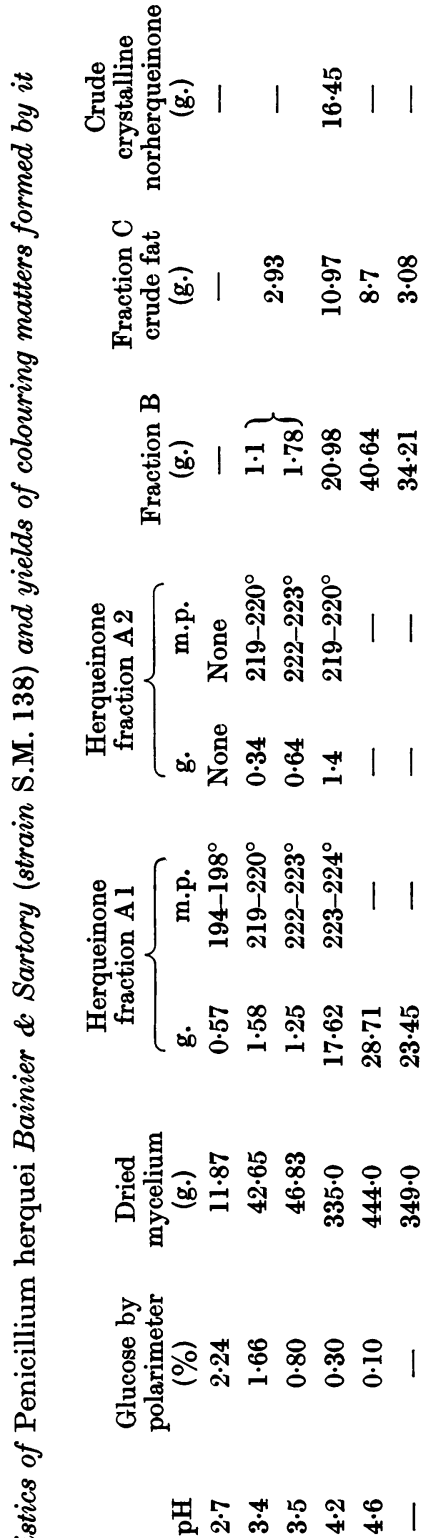

\&ี

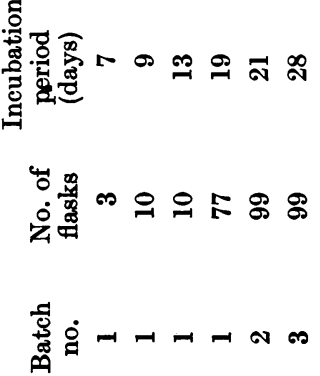




\section{HERQUEINONE}

Most of the preparations of herqueinone which separate directly from the evaporated $\mathrm{CHCl}_{3}$ mycelial extracts melt in the region of $223^{\circ}$ and are sufficiently pure for preparative purposes. Herqueinone was purified for analysis in the following way: $3 \mathrm{~g}$. (batch 1; 77 flasks; fraction A 1, m.p. $\left.223-224^{\circ}\right)$ were dissolved in boiling $\mathrm{CHCl}_{3}(100 \mathrm{ml}$.), filtered and cooled to crystallize, giving red crystals (1.58 g.), m.p. $224^{\circ}$, which were recrystallized from ethanol (50 ml.). Herqueinone $(0 \cdot 73 \mathrm{~g}$.) was thus obtained as long red needles, m.p. $226^{\circ}$ (decomp.), unchanged on further crystallization. (Found: N, S, Cl, nil; C, 64.2, 64.2; H, 5.4, 5.3; $C-\mathrm{CH}_{3}, 7 \cdot 3$. Calc. for $\mathrm{C}_{20} \mathrm{H}_{20} \mathrm{O}_{7}: \mathrm{C}, 64.5 ; \mathrm{H}, 5 \cdot 4$; $2 \mathrm{C} \cdot \mathrm{CH}_{3}, 8 \cdot 1 \%$.) Six methoxyl estimations varied from 8.35 to $9 \cdot 46 \%$, with an average of $8 \cdot 86 \%$; calc. for $1 \mathrm{OCH}_{3}$, $8.34 \%$. Stodola et al. (1951) describe similar results. $[\alpha]_{\mathrm{D}}^{22}+440^{\circ} \pm 40^{\circ} ;[\alpha]_{6461}^{22}+640^{\circ} \pm 20^{\circ}$, in ethanol $(c, 0.063)$. Owing to the relatively slight solubility of herqueinone and its derivatives in organic solvents and the intense colour of the solutions obtained, the determination of their optical rotations is difficult and is subject to a large error.

The ultraviolet absorption spectrum of herqueinone in ethanol solution showed the following maxima: $\lambda_{\max } 220$, $250,314,416 \mathrm{~m} \mu$. $(\log \epsilon 4 \cdot 29,4 \cdot 09,4 \cdot 47,3 \cdot 66$ respectively).

Herqueinone crystallizes in brick-red needles from $\mathrm{CHCl}_{3}$, ether, ethanol and ethyl acetate, being fairly soluble at room temperature in all four solvents, e.g. $1 \mathrm{~g}$. dissolves in $175 \mathrm{ml}$. of ethanol. It is insoluble in light petroleum and water. It sublimes in high vacuum at 175$190^{\circ}$ in crystalline form but with slight decomposition.

Herqueinone dissolves in $2 \mathrm{~N}-\mathrm{NaOH}$, giving a deeporange solution fading to pale yellow in less than 1 min., but is not soluble in aqueous $\mathrm{Na}_{2} \mathrm{CO}_{3}$. It also dissolves readily in conc. $\mathrm{HCl}$, giving a reddish orange solution, and in cold conc. $\mathrm{H}_{2} \mathrm{SO}_{4}$, giving a rather weak orange solution with a slight yellow fluorescence. On standing, the solution darkens in colour and takes on a strong green fluorescence. A saturated ethanolic solution of herqueinone which is not acid to litmus gave the following reactions: with ethanolic $\mathrm{FeCl}_{3}$, an intense black colour which appears as a brownish olive colour in very dilute solution; with saturated bromine water, decolorization and the separation of a colourless crystalline product; with Brady's reagent (0.32\% 2:4dinitrophenylhydrazine in aqueous $2 \mathrm{~N}-\mathrm{HCl}$ ), the formation of red needles of unchanged herqueinone. A solution of herquienone in acetic acid, initially red in colour, quickly becomes orange yellow on the addition of $\mathrm{Zn}$ dust.

isoHerqueinone. In an unsuccessful attempt to methylate herqueinone with methyl iodide, a mixture of herqueinone (1 g.), methyl iodide (5 g.), anhydrous $\mathrm{K}_{2} \mathrm{CO}_{3}(5 \mathrm{~g}$.) and dry acetone $(100 \mathrm{ml}$.) was refluxed for $8 \mathrm{hr}$. and was then filtered while still hot. The acetone filtrate, which still gave a strong ferric colour, was evaporated to dryness in vacuo and the residue was extracted with water and filtered. The aqueous filtrate was acidified and extracted with ether. The ethereal extract was evaporated, giving orange needles $(0.27 \mathrm{~g}$.), m.p. $238^{\circ}$. This product was crystallized thrice from ethanol and gave isoherqueinone as orange needles, m.p. 248-249 ${ }^{\circ}$, and strongly depressing the m.p. of herqueinone $\left(226^{\circ}\right)$ on admixture with it. (Found: C, 64.3; H, 5.4; $\mathrm{OCH}_{3}, 7.9$. $\mathrm{C}_{20} \mathrm{H}_{20} \mathrm{O}_{7}$ requires $\mathrm{C}, 64.5 ; \mathrm{H}, 5.4 ; 1 \mathrm{OCH}_{3}$, $8.3 \%$.) The substance does not dissolve in $\mathrm{N}-\mathrm{Na}_{2} \mathrm{CO}_{3}$, but dissolves in aqueous $2 \mathrm{~N}-\mathrm{NaOH}$, giving a deep-orange solution, which fades to pale yellow in less than 1 min. It gives reactions with cold conc. $\mathrm{H}_{2} \mathrm{SO}_{4}$ and $\mathrm{FeCl}_{3}$ in ethanol which are indistinguishable from those given by herqueinone with the same reagents. It is optically inactive, $[\alpha]_{\mathrm{D}}^{20} \mathrm{nil}$, in ethanol $(c, 0 \cdot 045)$. isoHerqueinone was also formed when the process was repeated, $(a)$ using dry benzene $(200 \mathrm{ml}$.) in place of acetone $(100 \mathrm{ml}$.$) and (b)$ omitting the methyl iodide and heating the herqueinone$\mathrm{K}_{2} \mathrm{CO}_{3}$-acetone mixture for only $1 \mathrm{hr}$.

The infrared absorption spectra of herqueinone and isoherqueinone were kindly determined for us by $\operatorname{Dr} \mathrm{K}$. T. Potts, of the National Institute for Medical Research, Mill Hill. The spectra were measured in $\mathrm{CHCl}_{3}$ solution (0.5\%) in a $1 \mathrm{~mm}$. cell on a Perkin Elmer Model 21 spectrophotometer with a rock-salt prism. The spectra of the two substances were identical within the limits of experimental error and showed the following main absorption bands: $3640 \mathrm{~m}, 3570 \mathrm{~s}, 3300 \mathrm{~m}, 2980 \mathrm{~s}, 1625 \mathrm{~s}, \mathrm{~cm}^{-1}$ (s = strong, $\mathbf{m}=$ medium absorption).

Deoxyherqueinone. $\mathrm{Zn}$ dust (2 g.) was added in small portions during $15 \mathrm{~min}$. to a solution of herqueinone $(1 \mathrm{~g}$.) in glacial acetic acid $(150 \mathrm{ml}$.) at room temp. The mixture was filtered and the orange-yellow non-fluorescent filtrate was poured into water $(300 \mathrm{ml}$.), giving a yellow precipitate which was collected, thoroughly extracted with aqueous $\mathrm{N}$-HCl $(50 \mathrm{ml}$.), washed with water and dried $(0.77 \mathrm{~g}$.$) ;$ m.p. 235-237 . The dry yellow powder was repeatedly crystallized from benzene, giving deoxyherqueinone as yellow plates, m.p. 240-241 ${ }^{\circ}$. (Found, on sample dried at $100^{\circ}$ in high vacuum with no loss in weight: $\mathrm{C}, 67 \cdot 3 ; \mathrm{H}, \mathbf{5 \cdot 6}$; $\mathrm{OCH}_{3}, 8 \cdot 4,8 \cdot 85 . \mathrm{C}_{20} \mathrm{H}_{20} \mathrm{O}_{6}$ requires $\mathrm{C}, 67 \cdot 4 ; \mathrm{H}, 5 \cdot 7 ; 1 \mathrm{OCH}_{3}$, $8.7 \%$.) $[\alpha]_{\mathrm{D}}^{22}+64^{\circ} ;[\alpha]_{5461}^{22}+68^{\circ}$ in acetic acid $(c, 0 \cdot 50)$. It is soluble in aqueous $2 \mathrm{~N}-\mathrm{NaOH}$, giving a pale-yellow solution, but does not dissolve in $\mathrm{Na}_{2} \mathrm{CO}_{3}$. It dissolves in cold conc. $\mathrm{H}_{2} \mathrm{SO}_{4}$ to an immediate bright-yellow solution with an intense yellowish green fluorescence. It gives in ethanol an intense brownish olive ferric colour which is indistinguishable from that given by herqueinone tested alongside.

Methylation of herqueinone with dimethyl sulphate. A mixture of herqueinone ( $2 \mathrm{~g}$.$) , dry acetone (200 \mathrm{ml}$.), dimethyl sulphate $\left(20 \mathrm{ml}\right.$.) and anhydrous $\mathrm{K}_{2} \mathrm{CO}_{3}(40 \mathrm{~g}$.) was boiled under a reflux condenser, fitted with a $\mathrm{CaCl}_{2}$ guard tube, for $2 \frac{1}{2} \mathrm{hr}$., when the clear supernatant, initially red, had become pale-yellow in colour and ceased to give a ferric reaction.

The mixture, while still hot, was filtered on a Büchner funnel. The residue in the funnel was washed with acetone and then with water $(500 \mathrm{ml}$.). The undissolved portion $(0 \cdot 30 \mathrm{~g}$.) was combined with similar material $(0 \cdot 115 \mathrm{~g}$.) from the acetone filtrate (see below) and was purified by crystal. lization from glacial acetic acid $(225 \mathrm{ml}$.) and sublimation (no residue) in high vacuum at $270-295^{\circ}$. Trimethylherqueinone $A$ was thus obtained as pale-yellow rods, m.p. $345^{\circ}$ with the formation of a sublimate, which itself resublimes at $325-330^{\circ}$. (Found: $\mathrm{C}, 66.55 ; \mathrm{H}, 6 \cdot 7 ; \mathrm{OCH}_{3}$, 30.1. $\mathrm{C}_{23} \mathrm{H}_{26} \mathrm{O}_{7}$ requires $\mathrm{C}, 66 \cdot 7 ; \mathrm{H}, 6 \cdot 3 ; 4 \mathrm{OCH}_{3}$, one of which is present in herqueinone, $29.95 \%$.) Trimethylherqueinone $A$ is optically inactive, $[\alpha]_{\mathrm{D}}^{20} \mathrm{nil}$, in benzene $(c, 0 \cdot 25)$. It is insoluble in $2 \mathrm{~N}-\mathrm{NaOH}$ and gives no ferric colour in ethanolic solution.

The acetone filtrate and washings were evaporated in vacuo, and the yellow crystals of trimethylherqueinone $A$ ( $0 \cdot 115 \mathrm{~g}$., see above), which separated from the viscous residue, were collected by filtration. The resulting viscous filtrate was dissolved in ether $(100 \mathrm{ml}$.), and the ethereal solution was extracted with aqueous $2 \mathrm{~N}-\mathrm{NaOH}(3 \times 50 \mathrm{ml}$.) 
and then with water $(2 \times 50 \mathrm{ml}$.) and then evaporated to dryness. The viscous residue was stirred vigorously with aqueous $\mathrm{N}-\mathrm{NaOH}\left(300 \mathrm{ml}\right.$.) and set aside overnight at $0^{\circ}$. The solid which separated was collected, washed with water and dried $(1 \cdot 14 \mathrm{~g}$.$) . It was dissolved in ether and$ crystallized, by slow evaporation of the solvent, in colourless prisms $(0 \cdot 19$ g. $)$, m.p. $163-167^{\circ}$. Purification of this substance by crystallization from ether-light petroleum, b.p. $40-60^{\circ}$, and sublimation in high vacuum at $150-170^{\circ}$ gave trimethylherqueinone $B$ as colourless rods $(0 \cdot 13 \mathrm{~g}$.), m.p. $170-171^{\circ}$. (Found: C, 66.95; H, 6.3; $\mathrm{OCH}_{3}, 30 \cdot 0$. $\mathrm{C}_{23} \mathrm{H}_{26} \mathrm{O}_{7}$ requires $\mathrm{C}, 66 \cdot 7 ; \mathrm{H}, 6 \cdot 3 ; 4 \mathrm{OCH}_{3}$, one of which is present in herqueinone, $29.95 \%$.) Trimethylherqueinone $\mathrm{B}$ is optically inactive, $[\alpha]_{\mathrm{D}}^{20} \mathrm{nil}$, in benzene $(c, 0 \cdot 25)$. It is insoluble in $2 \mathrm{~N}-\mathrm{NaOH}$ and gives no ferric colour in ethanolic solution.

The only crystalline product isolated from methylation of herqueinone (1 g.) in acetone $(80 \mathrm{ml}$.) for $3 \mathrm{hr}$. with much smaller amounts of dimethyl sulphate $\left(0.9 \mathrm{ml}\right.$.) and $\mathrm{K}_{2} \mathrm{CO}_{3}$ (2 g.) was the yellow trimethyl ether A, m.p. $341^{\circ}$, which did not depress the m.p. of the specimen described above, m.p. $345^{\circ}$.

Bromine derivative from herqueinone. Saturated bromine water $(500 \mathrm{ml}$.) was added to a solution of herqueinone $(2 \mathrm{~g}$.$) in ethanol (350 \mathrm{ml}$.$) , and the mixture was held at 0^{\circ}$ overnight. The colourless crystalline material which separated was collected and dried (0.95 g.), m.p.175-176 ${ }^{\circ}$. By the further addition of bromine water $(250 \mathrm{ml}$.) and water $(500 \mathrm{ml}$.) to the filtrate, a second crop $(1 \cdot 27 \mathrm{~g}$.$) , m.p.$ 105-112 $2^{\circ}$ of colourless amorphous material, which could not be crystallized, was obtained. The crystalline material, m.p. $175-176^{\circ}$, was crystallized from $\mathrm{CHCl}_{3}$-ethanol and $\mathrm{CHCl}_{3}$-ether, and the bromine derivative was obtained as colourless needles, m.p. 189-190 (decomp.). (Found: C, $29 \cdot 1 ; \mathrm{H}, 2 \cdot 6 ; \mathrm{Br}, 48 \cdot 6 ; \mathrm{OCH}_{3}, 8 \cdot 2 .\left(\mathrm{C}_{4} \mathrm{H}_{4} \mathrm{O}_{2} \mathrm{Br}\right)_{n}$ requires $\mathrm{C}$ $29.3 ; \mathrm{H}, 2.5 ; \mathrm{Br}, 48 \cdot 7 ; 1 \mathrm{OCH}_{3}$ if $n=2,9.5 ; 1 \mathrm{OCH}_{3}$ if $n=3,6 \cdot 3 \%$.) The substance does not dissolve in aqueous $\mathrm{NaHCO}_{3}$, but dissolves slowly in $\mathrm{N}-\mathrm{NaOH}$. It is readily soluble in $\mathrm{CHCl}_{3}$, much less soluble in ethanol and almost insoluble in water. Its saturated ethanolic solution gives a moderate purplish brown ferric colour.

\section{Acid hydrolysis of herqueinone}

A slow stream of $\mathrm{CO}_{2}$ - and $\mathrm{O}_{2}$-free $\mathrm{N}_{2}$ was bubbled through a suspension of herqueinone $(1.0 \mathrm{~g}$.) in aqueous $2 \mathrm{~N}-\mathrm{H}_{2} \mathrm{SO}_{4}(150 \mathrm{ml}$.) contained in a flask fitted with a tap funnel and a short upright condenser. The effluent gases were first passed through a number of bubblers containing Brady's reagent and then through further bubblers containing standard aqueous $\mathrm{Ba}(\mathrm{OH})_{2}$. The contents of the flask were boiled gently and, soon after boiling commenced, a yellow precipitate, $\mathrm{A}$, began to appear in the Brady bubblers. Boiling was continued for 13-14 hr., after which time only a negligible amount of $\mathrm{CO}_{2}$ had been absorbed in the baryta bubblers. After about $9 \mathrm{hr}$. boiling, the cooling water was drained from the reflux condenser to facilitate the removal of volatile products from the reaction mixture, and water was slowly added through the tap funnel to replace the distillate. At the end of the hydrolysis, the contents of the reaction flask (hydrolysis product B) were held at $0^{\circ}$ overnight.

Treatment of yellow precipitate A. Isolation of the 2:4dinitrophenylhydrazone of methyl isopropyl ketone. The yellow precpitate $A$ in the Brady bubblers was collected by filtration, washed with water and dried $(0 \cdot 292$ g. $)$, m.p. $117^{\circ}$. It was purified by repeated crystallization from ethanol and was finally obtained as yellow needles, m.p. 122-123 ${ }^{\circ}$. (Found: $\mathrm{C}, 49 \cdot 8 ; \mathrm{H}, 5 \cdot 0 ; \mathrm{N}, 21 \cdot 0 . \mathrm{C}_{11} \mathrm{H}_{14} \mathrm{O}_{4} \mathrm{~N}_{4}$, i.e. the 2:4dinitrophenylhydrazone of $\mathrm{C}_{5} \mathrm{H}_{10} \mathrm{O}$, requires $\mathrm{C}, 49 \cdot 6 ; \mathrm{H}, 5 \cdot 3$; $\mathrm{N}, 21 \cdot 05 \%$.)

The melting point was not depressed by admixture with an authentic sample of the 2:4-dinitrophenylhydrazone of methyl isopropyl ketone. The distillate from an acid hydrolysis of herqueinone was extracted with ether. The residue left after careful removal of the ether was treated with semicarbazide hydrochloride. The product, after recrystallization from light petroleum (b.p. $60-80^{\circ}$ ), was methyl isopropyl ketone semicarbazone, m.p. 113-114 ${ }^{\circ}$, unchanged on admixture with an authentic specimen. (Found: C, 50.75; H, 9.0; N, 29.6. Calc. for $\mathrm{C}_{6} \mathrm{H}_{13} \mathrm{ON}_{3}: \mathrm{C}$, $50 \cdot 3 ; \mathrm{H}, 9 \cdot 15 ; \mathrm{N}, 29 \cdot 3 \%$.)

The formation of methyl isopropyl ketone on acid hydrolysis of herqueinone suggests the probable origin of the high methoxyl values found for herqueinone, i.e. from 8.35 to $9.46 \%$ (calc. for $1 \mathrm{OCH}_{3}, 8.34 \%$ ), since methyl isopropyl ketone gave $0 \cdot 7 \% \mathrm{OCH}_{3}$ in a Zeisel estimation.

Treatment of hydrolysis product $B$. Isolation of xanthoherquein. The contents of the reaction flask (hydrolysis product B) were filtered, washed with water and dried $\left(0 \cdot 70\right.$ g.), m.p. $290-293^{\circ}$ after sintering at $250-260^{\circ}$. This yellowish brown partially crystalline solid was repeatedly crystallized from aqueous methanol $(60: 40)$ and aqueous ethanol (50:50), giving finally golden-yellow needles, m.p. 295-296 ${ }^{\circ}$ (decomp.). (Found, on different samples dried to constant weight in high vacuum at $120-125^{\circ}: \mathrm{C}, 59 \cdot 3$, $59 \cdot 55 ; \mathrm{H}, 4 \cdot 1,4 \cdot 05 ; \mathrm{OCH}_{3}, 10 \cdot 1,10 \cdot 1 ; C \cdot \mathrm{CH}_{3}, 4 \cdot 7 . \mathrm{C}_{15} \mathrm{H}_{12} \mathrm{O}_{7}$ requires $\mathrm{C}, 59 \cdot 2 ; \mathrm{H}, 4 \cdot 0 ; 1 \mathrm{OCH}_{3}, 10 \cdot 2 ; 1 \mathrm{C}-\mathrm{CH}_{3}, 4.9 \%$.)

The course of the acid hydrolysis of herqueinone thus proceeds according to the equation

$$
\mathrm{C}_{20} \mathrm{H}_{20} \mathrm{O}_{7}+\mathrm{H}_{2} \mathrm{O} \rightarrow \mathrm{C}_{5} \mathrm{H}_{10} \mathrm{O}+\mathrm{C}_{15} \mathrm{H}_{12} \mathrm{O}_{7} \text {, }
$$

and we propose to name the $\mathrm{C}_{15} \mathrm{H}_{12} \mathrm{O}_{7}$ hydrolysis product xanthoherquein because of its colour.

Xanthoherquein is acid to litmus and is readily soluble in aqueous $\mathrm{NaHCO}_{3}$, giving a yellow solution which changes to orange-red on standing for several hours. Its solution in aqueous $2 \mathrm{~N}-\mathrm{NaOH}$, initially red in colour, quickly changes to orange-red and, on standing overnight, to brownish red. It dissolves in cold conc. $\mathrm{H}_{2} \mathrm{SO}_{4}$, giving a greenish yellow solution, slowly becoming orange, and with a strong green fluorescence which fades on long standing. It gives a strong olive-green ferric reaction in ethanolic solution. Its ultraviolet spectrum in ethanol solution showed the following maxima: light-absorption maxima $\lambda 222,370$, 387, 262, 277 m $\mu$. (log $\epsilon, 4.46,4 \cdot 19,4 \cdot 23,4 \cdot 20,3.98$ respectively; $\sim$ = point of inflexion).

Xanthoherquein perchlorate. A few drops of $60 \%$ perchloric acid were added to a suspension of xanthoherquein $(0.20 \mathrm{~g}$.) in hot glacial acetic acid $(10 \mathrm{ml}$.), when the substance immediately dissolved, forming an orangeyellow solution. Additional perchloric acid (1 ml.) was now added and, on cooling, xanthoherquein perchlorate crystallized. It was recrystallized from acetic acid-perchloric acid as rosettes of dark-red rectangular plates, which on drying in vacuo at $100^{\circ}$ changed colour to orange-brown (0.16 g.), m.p. $244^{\circ}$ (decomp.). (Found: C, 42.9; H, 3.5; $\mathrm{OCH}_{3}, 7 \cdot 1$; $\mathrm{Cl}, 8 \cdot 5$. $\mathrm{C}_{15} \mathrm{H}_{12} \mathrm{O}_{7}, \mathrm{HClO}_{4}, \mathrm{H}_{2} \mathrm{O}$ requires $\mathrm{C}, 42 \cdot 6 ; \mathrm{H}, 3 \cdot 6$; $1 \mathrm{OCH}_{3}, 7 \cdot 3 ; \mathrm{Cl}, 8 \cdot 4 \%$.) 
Xanthoherquein tetramethyl ether. A mixture of xanthoherquein $\left(0.10 \mathrm{~g}\right.$.), anhydrous $\mathrm{K}_{2} \mathrm{CO}_{3}(2 \mathrm{~g}$. $)$, dimethyl sulphate $(1 \mathrm{ml}$.) and dry acetone $(10 \mathrm{ml}$.) was boiled under reflux for $1 \mathrm{hr}$. Acetone was then removed by evaporation, and water $(20 \mathrm{ml}$.) was added to the residue and vigorously shaken. The undissolved dark-yellow residue was collected $(0 \cdot 1 \mathrm{~g}$.), washed with water, dried and crystallized to constant m.p. from methanol, giving xanthoherquein tetramethyl ether as bright-yellow needles, m.p. 141-142 ${ }^{\circ}$. (Found, on material dried in high vacuum at $95^{\circ}$ without loss in weight: $\mathrm{C}, 63.4 ; \mathrm{H}, 5 \cdot 7 ; \mathrm{OCH}_{3}, 42 \cdot 95,42 \cdot 6 ; C-\mathrm{CH}_{3}$, 4.9. $\mathrm{C}_{19} \mathrm{H}_{20} \mathrm{O}_{7}$ requires $\mathrm{C}, 63.3 ; \mathrm{H}, 5.6 ; 5 \mathrm{OCH}_{3}, 43.05$; $1 C-\mathrm{CH}_{3}, 4 \cdot 2 \%$.) Its solution in cold conc. $\mathrm{H}_{2} \mathrm{SO}_{4}$ is bright golden-yellow in colour without fluorescence. It gives a colour with ethanolic $\mathrm{FeCl}_{3}$ which is brown by transmitted light and olive brown by reflected light. It is insoluble in aqueous $\mathrm{NaHCO}_{3}, \mathrm{Na}_{2} \mathrm{CO}_{3}$ or $2 \mathrm{~N}-\mathrm{NaOH}$. However, when its solution in ether is shaken with aqueous $2 \mathrm{~N}-\mathrm{NaOH}$, the substance is slowly extracted into the aqueous alkali, from which, on acidification, it is precipitated (bright-yellow needles from methanol, m.p. 141-142 $2^{\circ}$. On the contrary, it is not extracted from $\mathrm{CHCl}_{3}$ solution by aqueous $2 \mathrm{~N}-\mathrm{NaOH}$.

Ferrichloride of xanthoherquein tetramethyl ether. The methyl ether $(70 \mathrm{mg}$.) was dissolved in glacial acetic acid $\left(3 \mathrm{ml}\right.$.), and a solution of $\mathrm{FeCl}_{3}(70 \mathrm{mg}$.) in conc. $\mathrm{HCl}(5 \mathrm{ml}$.) was added. The resulting crystals were collected and recrystallized from glacial acetic acid-conc. $\mathrm{HCl}$ containing a little $\mathrm{FeCl}_{3}$ and the ferrichloride of xanthoherquein tetramethyl ether was obtained as orange-brown needles (55 mg.), m.p. 158-159 ${ }^{\circ}$ (decomp.). (Found: C, 41.1; H, 4.1; Cl, $24 \cdot 85 ; \mathrm{Fe}, 10 \cdot 1 ; \mathrm{OCH}_{3}, 27 \cdot 3 . \mathrm{C}_{19} \mathrm{H}_{20} \mathrm{O}_{7}, \mathrm{HFeCl}_{4}$ requires $\mathrm{C}, 40 \cdot 8 ; \mathrm{H}, 3 \cdot 8 ; \mathrm{Cl}, 25 \cdot 4 ; \mathrm{Fe}, 10 \cdot 0 ; 5 \mathrm{OCH}_{3}, 27 \cdot 8 \%$.)

\section{Alkaline hydrolysis of herqueinone}

A solution of herqueinone $(0.5 \mathrm{~g}$.) in aqueous $2 \mathrm{~N}-\mathrm{NaOH}$ $\left(40 \mathrm{ml}\right.$.) was boiled in a stream of purified $\mathrm{N}_{2}$ in the same apparatus as was used for the acid hydrolysis of herqueinone. A yellow precipitate appeared in the Brady bubblers soon after boiling commenced. Precipitation appeared to be complete after $0.5 \mathrm{hr}$. and the hydrolysis was terminated after $1 \mathrm{hr}$. The yellow precipitate was collected (97 mg.), m.p. 141-143 ${ }^{\circ}$, and purified by crystallization from methanol, giving acetaldehyde 2:4-dinitrophenylhydrazone as golden plates, m.p. $164 \cdot 5-166^{\circ}$, not depressed on admixture with an authentic specimen. (Found: C, 42.95; $\mathrm{H}, 3.6$. Calc. for $\mathrm{C}_{8} \mathrm{H}_{8} \mathrm{O}_{4} \mathrm{~N}_{4}: \mathrm{C}, 42.9$; $\mathrm{H}, 3.6 \%$.) Acidification of the alkaline hydrolysate produced a copious precipitate from which, however, no crystalline substance could be isolated.

It thus appears that alkaline hydrolysis of herqueinone follows a different course from that of the acid hydrolysis.

\section{NORHERQUEINONE}

The crystalline brick-red colouring matter (16.45 g.; batch 1, 77 flasks), obtained by ether extraction of the $\mathrm{CHCl}_{3}$-extracted mycelium, was fractionated by boiling portions of it for $10 \mathrm{~min}$. with ethanol $(250 \mathrm{ml} . / \mathrm{g}$.). The mixture was filtered hot and the undissolved portion $(0 \cdot 27$ g. $/ 2$ g. $)$, m.p. $279^{\circ}$ (decomp.), was recrystallized from glacial acetic acid $(1 \mathrm{l} . / \mathrm{g}$.$) , giving norherqueinone in small red$ needles, m.p. $279^{\circ}$ (decomp.). (Found: N, S, Cl, nil; C, 64.0, $63 \cdot 8,63 \cdot 7,63 \cdot 6 ; \mathrm{H}, 5 \cdot 0,5 \cdot 3,5 \cdot 0,5 \cdot 0 ; C \cdot \mathrm{CH}_{3}, 10 \cdot 35 ; \mathrm{OCH}_{3}$, $0 \cdot 80$. $\mathrm{C}_{19} \mathrm{H}_{18} \mathrm{O}_{7}$ requires $\mathrm{C}, 63 \cdot 7 ; \mathrm{H}, 5 \cdot 1 ; 3 \mathrm{C} \cdot \mathrm{CH}_{3}, 12.5$;
$2 C \cdot \mathrm{CH}_{3}, 8 \cdot 4 \%$.) $[\alpha]_{\mathrm{D}}^{23}+1080^{\circ} \pm 60^{\circ} ;[\alpha]_{5461}^{23}+1120^{\circ} \pm 60^{\circ}$ in pyridine $(c, 0.048)$. Norherqueinone is only slightly soluble in most of the usual organic solvents. It dissolves in aqueous $2 \mathrm{~N}-\mathrm{NaOH}$, giving a dark-red solution which rapidly fades to yellow. It is insoluble in aqueous $\mathrm{N}$ $\mathrm{Na}_{2} \mathrm{CO}_{3}$, and cannot be extracted by this reagent from its $\mathrm{CHCl}_{3}$ or $n$-butanol solution. Its solution in cold conc. $\mathrm{H}_{2} \mathrm{SO}_{4}$, initially reddish orange in colour, changes on standing to reddish brown with a strong green fluorescence. It gives an intense olive-green ferric colour in ethanolic solution. The crystals of norherqueinone are light-sensitive, changing on exposure to daylight to a dark-brown colour on the surface.

The hot ethanolic filtrate obtained above by extraction of the crude crystalline colouring matter $(250 \mathrm{ml} . / \mathrm{g}$.) deposited a small amount of norherqueinone on cooling, and this was collected by filtration. The filtrate was evaporated in vacuo to a small volume and a pale-yellow solid separated on standing. This crystallized from methanol as stout, colourless, tetragonal prisms, m.p. $120-124^{\circ}$, undepressed on admixture with authentic mesoerythritol. Yield, $80 \mathrm{mg}$. from $1 \cdot 2 \mathrm{~g}$. of crude colouring matter. (Found: C, 39.3; H, 8.2. Calc. for $\mathrm{C}_{4} \mathrm{H}_{10} \mathrm{O}_{4} ; \mathrm{C}, 39 \cdot 3 ; \mathrm{H}, 8 \cdot 25 \%$.) The substance is very soluble in water, gives no colour with $2 \mathrm{~N}-\mathrm{NaOH}$, conc. $\mathrm{H}_{2} \mathrm{SO}_{4}$ or $\mathrm{FeCl}_{3}$ and does not reduce Fehling's solution.

isoNorherqueinone. A mixture of norherqueinone $\left(0.5\right.$ g.), anhydrous $\mathrm{K}_{2} \mathrm{CO}_{3}(1 \mathrm{~g}$.) and dry acetone $(300 \mathrm{ml}$.) was refluxed for $1 \mathrm{hr}$. The norherqueinone soon dissolved, giving a brown-red solution which was filtered while still hot. The filtrate was evaporated to dryness and the residual dark red-brown solid was dissolved in a little cold water and acidified with $\mathrm{HCl}$. The resulting bright-red crystalline solid, on recrystallization from acetone or methanol, gave isonorherqueinone $\left(0 \cdot 20 \mathrm{~g}\right.$.) as dark-red needles, m.p. $284^{\circ}$ (decomp.). (Found: C, 63.9; H, 4.9. $\mathrm{C}_{19} \mathrm{H}_{18} \mathrm{O}_{7}$ requires $\mathrm{C}$, $63.7 ; \mathrm{H}, 5.1 \%$.) isoNorherqueinone gives colour reactions with $2 \mathrm{~N}-\mathrm{NaOH}$, cold conc. $\mathrm{H}_{2} \mathrm{SO}_{4}$ and $\mathrm{FeCl}_{3}$ in ethanol which are indistinguishable from those given by norherqueinone with the same reagents. $[\alpha]_{\mathrm{D}}^{22}-730^{\circ} \pm 60^{\circ}$, $[\alpha]_{5461}^{22}-790^{\circ} \pm 60^{\circ}$ in pyridine $(c, 0.048)$.

Methylation of norherqueinone with dimethyl sulphate. A mixture of norherqueinone $\left(2 \mathrm{~g}\right.$.), anhydrous $\mathrm{K}_{2} \mathrm{CO}_{3}$ $(6 \mathrm{~g}$.$) , dimethyl sulphate (2.8 \mathrm{ml}$.) and acetone $(200 \mathrm{ml}$.) was refluxed for $18 \mathrm{hr}$. The acetone solution, initially dark red but now pale yellow in colour, was separated from insoluble material by filtration. The filtrate was evaporated to dryness and the residue was triturated with ether and filtered. No crystalline material could be isolated, either by fractionation with $2 \mathrm{~N}-\mathrm{NaOH}$ or by chromatography on alumina in benzene, from the ether filtrate, which contained much gummy material (cf. methylation of herqueinone). The pale-yellow solid ( $0 \cdot 174$ g.; m.p. about $\left.330^{\circ}\right)$ remaining undissolved in the ether was purified by crystallization from benzene-light petroleum (b.p. $60-80^{\circ}$ ), followed by sublimation in high vacuum at $270^{\circ}$, and a final crystallization from glacial acetic acid gave norherqueinone tetramethyl ether as pale-yellow plates, m.p. $341^{\circ}$, which did not depress the m.p. of trimethylherqueinone A, m.p. $345^{\circ}$.

\section{Acid hydrolysis of norherqueinone}

A suspension of norherqueinone ( 1 g.) in $2 \mathrm{~N}-\mathrm{H}_{2} \mathrm{SO}_{4}$ (150 ml.) was boiled in $\mathrm{N}_{2}$ for $96 \mathrm{hr}$. in the same apparatus and under similar conditions to those used in the acid 
hydrolysis of herqueinone. Only a negligible amount of $\mathrm{CO}_{2}$ was evolved. The yellow precipitate in the Brady bubblers $\left(0.402 \mathrm{~g} . \equiv 86 \%\right.$ of the theoretical; m.p. $\left.118-119^{\circ}\right)$ was crystallized from methanol, giving orange needles, m.p. 122-123 ${ }^{\circ}$, not depressed on admixture with authentic methyl isopropyl ketone 2:4-dinitrophenylhydrazone.

The solid in the hydrolysis flask, initially dark red but now reddish yellow in colour, was collected, washed and dried ( $0 \cdot 88 \mathrm{~g}$.). It was purified by repeated sublimation in high vacuum at about $250^{\circ}$, giving norxanthoherquein as yellow-orange plates, which darken slowly on heating above $300^{\circ}$ and do not melt below $360^{\circ}$. (Found: $\mathrm{C}, 58 \cdot 2$, $58 \cdot 2 ; \mathrm{H}, 3 \cdot 6,3 \cdot 5 ; \mathrm{OCH}_{3}, 0 \cdot 3 ; C-\mathrm{CH}_{3}, 5 \cdot 6 . \mathrm{C}_{14} \mathrm{H}_{10} \mathrm{O}_{7}$ requires $\mathrm{C}, 57 \cdot 9 ; \mathrm{H}, 3.5 ; 1 \mathrm{OCH}_{3}, 10 \cdot 7 ; 1 \mathrm{C} \cdot \mathrm{CH}_{3}, 5 \cdot 2 \%$.) Norxanthoherquein is only very slightly soluble in all the usual organic solvents. It dissolves in saturated aqueous $\mathrm{NaHCO}_{3}$ and in $\mathrm{N}-\mathrm{Na}_{2} \mathrm{CO}_{3}$, forming a pale-yellow solution, which rapidly darkens in colour, and in aqueous $2 \mathrm{~N}-\mathrm{NaOH}$, giving an orange solution. In cold conc. $\mathrm{H}_{2} \mathrm{SO}_{4}$ it gives a yellow solution with an intense yellow-green fluorescence. It gives an olive-green ferric colour in ethanol, changing to purple-brown on standing.

Norxanthoherquein can be prepared more expeditiously as follows: A mixture of norherqueinone (l g.), water $\left(60 \mathrm{ml}\right.$ ), glacial acetic acid $\left(30 \mathrm{ml}\right.$.) and conc. $\mathrm{H}_{2} \mathrm{SO}_{4}$ $(30 \mathrm{ml}$.) was refluxed for $16 \mathrm{hr}$. The norherqueinone dissolved immediately on heating to a dark-red solution, which had changed to yellow-brown at the end of the hydrolysis. The mixture was then partly concentrated in vacuo, and the concentrate was poured into water $(600 \mathrm{ml}$.) to which sodium acetate $(20$ g.) was added. The resulting flocculent brown precipitate was filtered off, washed well with water and dried. The crude norxanthoherquein $(0.84 \mathrm{~g}$.) was purified by sublimation as described above. The distillate from the vacuum concentration of the hydrolysis mixture was neutralized with $\mathrm{NaOH}$ and extracted with ether. On removal of the solvent from the ether extract, methyl isopropyl ketone remained as a fragrant colourless liquid.

Methylation of norxanthoherquein. An etheral solution of diazomethane (from $10 \mathrm{~g}$. of nitrosomethylurea) was slowly added to a suspension, cooled in ice, of norxanthoherquein $(1 \mathrm{~g}$.) in methanol $(20 \mathrm{ml}$.). A vigorous evolution of gas occurred and the solid dissolved. The solution was kept at $0^{\circ}$ for $24 \mathrm{hr}$. A further similar amount of diazomethane was then added and the solution was again kept at $0^{\circ}$ for $24 \mathrm{hr}$. Excess of diazomethane was destroyed by addition of acetic acid. The mixture was then washed with water and finally extracted with aqueous $2 \mathrm{~N}-\mathrm{NaOH}$. On acidification of the alkaline extract, a yellow crystalline solid (0.16 g.) was precipitated and collected. It was recrystallized from methanol, giving pale-yellow needles, m.p. $140-141^{\circ}$, not depressed on admixture with xanthoherquein tetramethyl ether, m.p. 141-142 ${ }^{\circ}$, and giving identical colour reactions. (Found: C, 63.35; H, 5.7; $\mathrm{OCH}_{3}, 42 \cdot 7$. Calc. for $\mathrm{C}_{10} \mathrm{H}_{20} \mathrm{O}_{7}: \mathrm{C}, 63 \cdot 3 ; \mathrm{H}, 5 \cdot 6 ; 5 \mathrm{OCH}_{3}$,
43.05\%.) The alkali-extracted ethereal solution was dried $\left(\mathrm{MgSO}_{4}\right)$ and evaporated, giving a brown oil which has not been obtained in crystalline form.

\section{SUMMARY}

1. The dried mycelium of laboratory cultures of a typical strain of Penicillium herquei Bainier \& Sartory has yielded, by solvent extraction, about $17 \%$ of its weight of a complex mixture of crude colouring matters.

2. Minor constituents of this mixture are physcion (4:5-dihydroxy-7-methoxy-2-methylanthraquinone) and the colourless tetrahydric alcohol, mesoerythritol.

3. Two of the major constituents are the hitherto undescribed norherqueinone, $\mathrm{C}_{19} \mathrm{H}_{18} \mathrm{O}_{7}$, dark-red needles, m.p. $279^{\circ}$, and its monomethyl ether, herqueinone, $\mathrm{C}_{20} \mathrm{H}_{20} \mathrm{O}_{7}$, brick-red needles, m.p. $226^{\circ}$. Both substances are strongly dextrorotatory.

4. A number of functional derivatives of herqueinone and norherqueinone are described.

5. Acid hydrolysis of herqueinone gives one molecule each of methyl isopropyl ketone, $\mathrm{C}_{5} \mathrm{H}_{10} \mathrm{O}$, and xanthoherquein, $\mathrm{C}_{15} \mathrm{H}_{12} \mathrm{O}_{7}$, golden-yellow needles, m.p. 295-296 ${ }^{\circ}$. Similar hydrolysis of norherqueinone gives the same ketone and norxanthoherquein, $\mathrm{C}_{\mathbf{1 4}} \mathrm{H}_{10} \mathrm{O}_{7}$, orange-yellow plates, m.p. above $360^{\circ}$.

6. Norxanthoherquein and xanthoherquein give the same pentamethyl ether, $\mathrm{C}_{14} \mathrm{H}_{5} \mathrm{O}_{2}\left(\mathrm{OCH}_{3}\right)_{5}$. Hence xanthoherquein is the monomethyl ether of norxanthoherquein.

\section{REFERENCES}

Birkinshaw, J. H., Chambers, A. R. \& Raistrick, H. (1942). Biochem. J. 36, 242.

Breen, J., Dacre, J. C., Raistrick, H. \& Smith, G. (1955). Biochem. J. 60, 618.

Howard, B. H. \& Raistrick, H. (1949). Biochem. J. 44, 227.

Howard, B. H. \& Raistrick, H. (1950). Biochem. J. 46, 49.

Howard, B. H. \& Raistrick, H. (1954a). Biochem. J. 56, 56.

Howard, B. H. \& Raistrick, H. (1954b). Biochem. J. 57, 212.

Oxford, A. E. \& Raistrick, H. (1935). Biochem. J. 29, 1599.

Raper, K. B. \& Thom, C. (1949). A Manual of the Penicillia. Baltimore: Williams \& Wilkins.

Stodola, F. H., Raper, K. B. \& Fennell, D. I. (1951). Nature, Lond., 167, 773. 